\title{
Functional electrolytic coatings of tin-nickel alloys for integrated circuits
}

\author{
V.S. KUBLANOVSKY ${ }^{1 *}$, V.N. NIKITENKO ${ }^{1}$ \\ ${ }^{1}$ V.I. Vernadskii Institute of General and Inorganic Chemistry of the NAS of Ukraine, \\ Palladina Ave. 32-34, 03680 Kyiv 142, Ukraine \\ * Corresponding author. Tel.: +380-44-4243311; e-mail: kublan@ukr.net
}

Received April 28, 2017; accepted June 27, 2017; available on-line April 1, 2018

The optimal composition of a polyligand ammonium-chloride-fluoride electrolyte and optimized electrolysis conditions for the deposition of functional tin-nickel alloy coatings are proposed. A tin-nickel alloy with a tin content of $65 \mathrm{wt} . \%$ and a nickel content of $35 \mathrm{wt} . \%$ was found to be the most promising alloy for replacing gold coating in microelectronics. It is shown that the obtained coatings are suitable for soldering using lowtemperature solders and acid-free fluxes, and for ultrasonic spot welding.

\section{Microelectronics / Functional coatings / Complex compounds / Electrodeposition / Tin-nickel alloy}

\section{Introduction}

In modern microelectronics, finishing coatings of nickel alloys, such as tin-nickel alloys, are widely used instead of gold coating, or as underlayer for gold, in the manufacture of printed-circuit boards, semiconductor devices and integrated circuits. These alloys do not diffuse into gold and other precious metals.

Gold coatings are characterized not only by valuable properties, but also by considerable disadvantages, such as relatively low hardness and wear resistance.

The functions performed by electrodeposited coatings in microelectronic devices are specific. The coatings must have uniform chemical composition and constant physico-mechanical, chemical and functional properties. They must have good wettability by solder and solderability when using low-temperature solders and acid-free fluxes for a long time (up to one year). This makes them suitable for ultrasonic spot welding and reliable during the operation of semiconductor devices and integrated circuits, since there is no peeling of the coating. The coating should not interact with oils, have a higher transition resistance than silver coatings, and not change during long-term operation of the device.

One of the simplest, well controllable, and most efficient methods for obtaining coatings of alloys such as tin-nickel alloys, is electrodeposition from aqueous solutions of complex compounds $[1,2]$. This is due to a number of advantages, which are inherent to electrolytes based on metal complexes. Firstly, such electrolytes are nontoxic, stable and easily recoverable. Secondly, complexing ligands of acidic type (primarily complexones) form a wide range of stable complex compounds with almost all metal ions thanks to their cyclic structure. They have a pronounced compatibility with weak-field ligands within the coordination sphere of the polyligand complex.

In modern electroplating technology, polyligand electrolytes [1] such as ammonium-fluoride, citrate, tartrate-trilonate and pyrophosphate-tartrate-glucinate electrolytes, are widely used to deposit tin-nickel alloys. The combination of properly chosen ligands for polyligand electrolytes allows controlling the rate of the electrode process, or stages of it, and hence the structure and properties of the deposited coatings [2,3].

Scientific criteria for choosing ligands for polyligand electrolytes and conditions of their compatibility within the same coordination sphere in the case of mixed-ligand complex compounds were formulated in [2]. An advantage of polyligand electrolytes is the high buffer capacity and hence slight alkalization of the cathode layer during longterm operation.

One of the main disadvantages of tin-nickel alloy coatings electrodeposited from ammonium-fluoride and pyrophosphate-tartrate-glucinate electrolytes (especially in down to $3 \mu \mathrm{m}$ thick thin layers) is the presence of strains. This leads to the formation of cracks on the surface of the coating, and hence to mechanical destruction during the operation.

According to the phase diagram [4,5], tin and nickel form intermetallics of the compositions $\mathrm{Ni}_{3} \mathrm{Sn}$, $\mathrm{Ni}_{3} \mathrm{Sn}_{2}$ and $\mathrm{Ni}_{3} \mathrm{Sn}_{4}$. It should be emphasized that 
electrodeposited thin tin-nickel alloy coating is formed by the single-phase intermetallic compound $\mathrm{NiSn}$, which can only be obtained by the electrolytic method [6].

The aim of this work was to develop a process for the deposition of functional tin-nickel alloy coatings of required composition, which are suitable for ultrasonic spot welding, and can replace gold coatings in semiconductor devices and integrated circuit packages.

Based on the results of preliminary experiments, we opted for a polyligand ammonium-chloridefluoride electrolyte with addition of an organic surfactant OC-20 (polyethylene glycol monoalkyl ethers based on primary fatty acids $\mathrm{C}_{n} \mathrm{H}_{2 n+1} \mathrm{O}\left(\mathrm{C}_{2} \mathrm{H}_{4} \mathrm{O}\right)_{m} \mathrm{H}$, where $n=18$ (grade $\mathrm{A}$ ), 14-18 (grade B), or 16-18 (grade $\mathrm{C}$ ); $m=20$ ). The tin-nickel alloy coatings were deposited from the polyligand ammonium-chloride-fluoride complex salt electrolyte, with and without addition of the organic surfactant OC-20. The fluoride ions act as ligand for tin(II) ions and the ammonium ions for nickel(II) ions.

\section{Experimental procedure}

The tin-nickel alloy coatings were deposited on copper and nickel foils and Kovar with $1.5 \times 2.5 \mathrm{~cm}^{2}$ surface area from an ammonium-chloride-fluoride electrolyte of the following composition $\left(\mathrm{g} \mathrm{L}^{-1}\right)$ : tin(II) chloride, 40-50; nickel(II) chloride, 250-300; ammonium fluoride, 35-40; sodium fluoride, 25-30. The experiments were performed with addition of an organic surfactant OC-20, 2-5 (a), or from an electrolyte without additive (b), at a direct current density of $0.5-2.0 \mathrm{~A} \mathrm{dm}^{-2}$ and a temperature of $50-80^{\circ} \mathrm{C}$. Graphite was used as anode. The electrolyte was prepared from analytically pure reagents.

Before the deposition of the tin-nickel alloy, the surface of the samples were degreased with soda and Vienna lime, etched in an $\mathrm{HCl}$ solution $\left(150 \mathrm{~g} \mathrm{~L}^{-1}\right)$ for 1-2 $\mathrm{s}$, activated in an $\mathrm{H}_{2} \mathrm{SO}_{4}$ solution $\left(50 \mathrm{~g} \mathrm{~L}^{-1}\right)$ for 1-2 s, and washed with distilled water.

The samples were weighed on a VLA-200 M analytical balance.

The morphology of the tin-nickel alloy coatings was studied on a Superprobe-733 scanning electron microscope (JEOL, Japan) with an X-ray microanalyzer at an accelerating voltage of $25 \mathrm{kV}$, and on a REM 101 scanning electron microscope.

The tin-nickel alloy coatings on Kovar were tested for corrosion resistance under atmospheric conditions, in seawater and in $10 \% \mathrm{HCl}$ and $\mathrm{H}_{2} \mathrm{SO}_{4}$ solutions.

The ultrasonic weldability of the coatings was checked on a DV-10-833 setup.

To test the suitability of the coating for ultrasonic spot welding, we used samples deposited on a copper substrate. Jumper wires were welded on a YeM-4020B automatic welding machine using an AK09PT-50 wire with an initial breaking strength of
$0.4 \mathrm{~N}$. The best results were obtained for samples deposited from the ammonium-chloride-fluoride electrolyte with addition of an organic surfactant OC-20.

\section{Results and discussion}

Scanning electron microscopy (SEM) images of electrolytic tin-nickel alloy coatings deposited from ammonium-chloride-fluoride electrolyte are presented in Fig 1. It should be emphasized that the coatings are characterized by the presence of well-formed and close-packed crystals, 1-2 $\mu \mathrm{m}$ large. The obtained coatings were homogeneous, without foreign inclusions such as metallic tin.

During the electrolysis, an alloy of equiatomic composition, NiSn, which is part of the solid solution based on the intermetallic compound $\mathrm{Ni}_{3} \mathrm{Sn}_{2}$ with a nickel content of 60 at.\%, is commonly formed [6].

It has been found that the main factors that determine the deposition of tin-nickel alloy coatings for semiconductor devices and integrated circuits from an ammonium-chloride-fluoride electrolyte of a given composition are the temperature of the electrolyte and the current density. At $30^{\circ} \mathrm{C}$ and low current density $\left(0.25 \mathrm{~A} \mathrm{dm}^{-2}\right)$, highly stressed, coarse-crystalline tinnickel alloy coatings were deposited from the electrolyte with addition of $2.0 \mathrm{~g} \mathrm{~L}^{-1}$ organic surfactant OC-20 (Fig. 1 (b)). The nickel content of the coating was about $7 \mathrm{wt} . \%$. Increasing the electrolyte temperature to $65-80^{\circ} \mathrm{C}$ (without addition of organic surfactant OC-20, or at an OC-20 content of $2-5 \mathrm{~g} \mathrm{~L}^{-1}$ ) at a direct current density of $0.75 \mathrm{~A} \mathrm{dm}^{-2}$ led to an increase of the nickel content of the alloy to 30-35 wt.\%. The coatings were characterized by a fine-crystalline structure and luster. Increasing the tin content of the NiSn alloy increases the probability of non-uniform composition of the coating and deteriorates its functional properties.

A slight deviation of the ratio of the main constituents of the electrolyte from the preset one did practically not affect the composition of the tin-nickel alloy. Decreasing the concentration of tin(II) or nickel(II) ions in the electrolyte sharply reduced the cathodic current yield of tin-nickel alloy. The current density only slightly affects the composition of the tinnickel alloy, but greatly affects its functional properties, especially internal stresses. The current yield of tin-nickel alloy was $95-99 \%$ for a current density of $1.0 \mathrm{~A} \mathrm{dm}^{-2}$ and a temperature of $70^{\circ} \mathrm{C}$. The alloy deposition rate at $1.0 \mathrm{~A} \mathrm{dm}^{-2}$ was $20 \mu \mathrm{m} \mathrm{h}^{-1}$.

Increasing the ammonium fluoride and sodium fluoride content of the electrolyte led to an increase of the stability of the tin(II) fluoride and fluoridechloride complexes $\mathrm{SnF}_{4}{ }^{2-}$ and $\mathrm{SnF}_{2} \mathrm{Cl}_{2}{ }^{2-}$, and hence to an increase of the nickel concentration in the alloy. It has been observed that the nature of the fluoride cation does practically not affect the composition of the tin-nickel alloy, but determines the physico- 
mechanical, chemical and functional properties of the deposited coatings. For instance, lustrous and brittle coatings were deposited from the electrolyte used here containing only ammonium fluoride, whereas matte coatings of increased ductility were deposited from an electrolyte containing sodium fluoride. When ammonium and sodium fluorides are present in the electrolyte at the same time, fine-crystalline ductile lustrous coatings are generally obtained, in which the proportion of tin is $65 \mathrm{wt} \%$ and that of nickel 35 wt. $\%$. The addition of tin(II) and nickel(II) sulfates, besides chlorides, to the ammonium-chloride-fluoride electrolyte also leads to a reduction of the brittleness of the tin-nickel alloy coatings. The obtained coatings are fine crystalline and show good adhesion to the substrate, higher ductility, high reflectivity, wear resistance, and corrosion resistance to aggressive media.

It has been found experimentally that, to obtain lustrous tin-nickel alloy coatings, the electrolyte must constantly be filtered because the electrolytic bath is very sensitive to impurities such as heavy metal ions (lead, cadmium, copper, iron, antimony, etc.), oils, fats, and various organic compounds.

To reduce the internal stresses and the brittleness of tin-nickel alloy coatings, and to impart ductility and luster to them, $n$-phenylsulfonic acid, 8-quinolinesulfonic acid, $o$-oxybenzoic sulfoacid, di-2-dimethylamino-5-pyridine methane, gelatin, and other additives are added to the ammonium-chloridefluoride electrolyte [7-10].

The ductility of the tin-nickel alloy coatings plays an important role, since its reduction increases the brittleness of testing terminals during soldering or ultrasonic welding and thereby the probability of their breaking during integrated circuit packaging.
It has been shown that the functional properties of tin-nickel alloy coatings containing more than $70 \mathrm{wt} \%$ tin do not comply with a number of technological requirements of coatings used in the manufacturing of semiconductor devices and integrated circuits. The data available on the functional properties of tin-nickel alloys allow making some assumptions about possible causes of failures that arise during the assembly and operation of semiconductor devices and integrated circuits. One such cause is the non-compliance of the composition of the alloy fabricated by electrolysis with technical requirements, which may be due to the deviations of the electrodeposition conditions from the required conditions.

During the assembly of semiconductor devices, a local temperature rise to $300^{\circ} \mathrm{C}$ takes place during soldering or ultrasonic welding. At this temperature, the unstable phase NiSn decomposes to form the intermetallic compounds $\mathrm{Ni}_{3} \mathrm{Sn}_{2}$ and $\mathrm{Ni}_{3} \mathrm{Sn}_{4}$ [6]. In this case the probability of decomposition of the supersaturated solid solution with separation of pure tin increases. The transformation temperature of the single-phase tin-nickel alloy decreases with increasing tin content of the alloy and is only $100^{\circ} \mathrm{C}$ for the alloy containing 70 wt.\% tin [6]. This may be a cause of coating delamination during the assembly of semiconductor devices and integrated circuit packaging. The formation of a two-phase structure changes the physico-mechanical, chemical and functional properties of the coating, leads to an increase of the hardness and strength of the tin-nickel alloy, and is accompanied by a reduction of the ductility. The brittleness of the coating increases and the probability of breaking of testing terminals during soldering or ultrasonic welding increases.

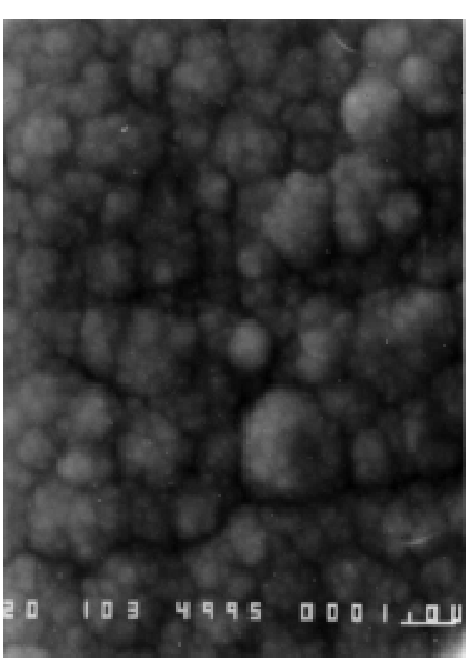

$a$

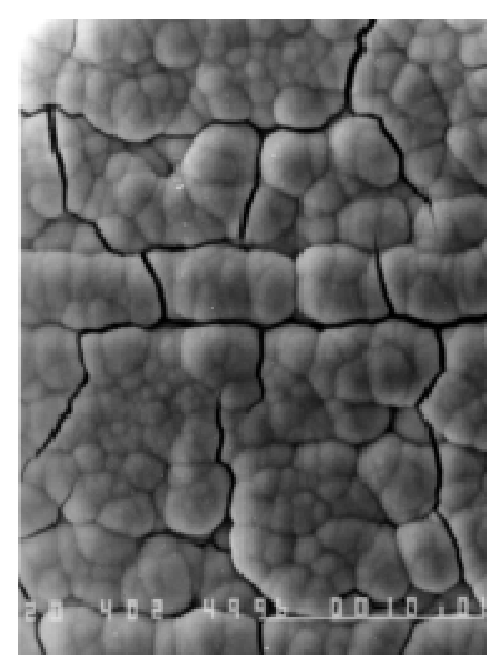

b

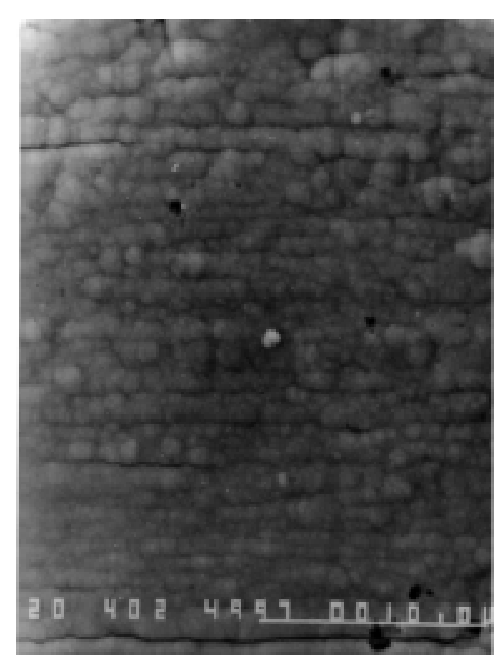

$c$

Fig. 1 SEM of electrolytic tin-nickel alloy coatings deposited from an ammonium-chloride-fluoride electrolyte with addition of $2.0 \mathrm{~g} \mathrm{~L}^{-1} \mathrm{OC}-20(a, b)$ and without additive $(c)$ at a current density of $0.25 \mathrm{~A} \mathrm{dm}^{-2}(b)$ and $0.50 \mathrm{~A} \mathrm{dm}^{-2}(a, c)$ and a temperature of $40^{\circ} \mathrm{C}(a, c)$ or $30^{\circ} \mathrm{C}(b)$. 
Taking in consideration the above-said, we conclude that the tin-nickel alloy with a tin content of $65 \mathrm{wt} . \%$ and a nickel content of $35 \mathrm{wt} . \%$ produces the most promising coating for application in microelectronics. In this coating, no traces of decomposition will be found at temperatures below $125^{\circ} \mathrm{C}$ even after 40 years [6]. Corrosion tests of tinnickel alloys in seawater and solutions simulating human sweat showed that the coatings do not lose solderability during a year. A correlation between the corrosion resistance of the coatings and their morphology was observed in [11]. Tests of electrolytic tin-nickel coatings on Kovar for the strength of a microwelded joint to an aluminum wire with a diameter of $30 \mu \mathrm{m}$ showed that 3-4 $\mu \mathrm{m}$ thick coatings had the best physicochemical properties. The mean fracture force of microwelded joint made by ultrasonic spot welding was 6.1-9.4 g with a variation coefficient of $22.5 \%$.

The obtained results indicate that the experimental conditions for tin-nickel alloy electrodeposition, viz the concentration ratio of the electrolyte constituents, the current density and the temperature, must be strictly respected. It is also necessary to check the alloy composition, perform a qualitative assessment of the condition of the surfaces to be welded or soldered, and adjust the conditions of the processes for the formation of joints.

The proposed method for the manufacture of semiconductor devices and integrated circuits has a number of advantages over the prototype golden coating with an underlying $2-3 \mu \mathrm{m}$ thick chemical nickel layer. The main advantage is the possibility to obtain corrosion-resistant single-phase tin-nickel alloy coating of a given composition maintaining the suitability for point ultrasound welding during one year. The other advantages are as follows: firstly, the time necessary to prepare the Kovar surface for coating is reduced; secondly, the process for the deposition of corrosion-resistant functional tin-nickel alloy coatings becomes simpler, since single-layer coating is deposited instead of double-layer coating; thirdly, the process enables the thickness of the protective coating, and, hence, its cost, to be reduced by a factor of 2-2.5.

\section{Conclusions and final remarks}

The optimal composition of a polyligand ammoniumchloride-fluoride electrolyte and experimental conditions for electrolysis deposition of functional tinnickel alloy coatings, suitable to be used instead of gold coatings in integrated circuit packages, have been proposed.
The effect of the ionic composition of the electrolyte without additives, and with addition of organic surfactant OS-20, and the experimental conditions on the structure and physicochemical and functional properties of tin-nickel alloy coatings, has been studied.

Electrolytic tin-nickel alloy coatings with a tin content of $65 \mathrm{wt} . \%$ are the most promising for application in microelectronics. The functional properties of the tin-nickel coatings ensure their suitability for ultrasonic spot welding with aluminum wire and reliability in hermetic sealing and operation of semiconductor devices and integrated circuits.

\section{Acknowledgments}

The publication is based on research financed by a grant of the Program on Fundamental Studies of the National Academy of Sciences of Ukraine, agreement No. 8-14, 2014.

\section{References}

[1] N.I. Globa, V.D. Prisyazhnyi, V.S. Kublanovsky, V.N. Nikitenko, Surf. Eng. Appl. Electrochem. 50 (2014) 280-284.

[2] V.V. Orekhova, F.K. Andryushchenko, Polyligand Electrolytes in Electroplating, Vysshaya Shkola, Khar'kov, 1979, 144 p. (in Russian).

[3] V.S. Kublanovsky, V.N. Nikitenko, Electrochim. Acta 56 (2011) 2110-2115.

[4] M. Hansen, K. Anderko, Constitution of Binary Alloys, McGraw-Hill Book Company, New York, 1958, vol. 2, 1488 p.

[5] R.P. Elliott, Constitution of Binary alloys, $1^{\text {st }}$ Supplement, McGraw-Hill Book Company, New York, 1968, vol. 2, 472 p.

[6] H. Enomoto, Y. Fujiwara, M. Izaki, H. Ono, J. Met. Finish. Soc. Jpn. 33(8) (1982) 369-374.

[7] N.T. Kudryavtsen, K.M. Tyutina, L.V. Kosmodamianskaya, Author's Certificate No. 310951 (USSR), Bull. 24, 1971.

[8] N.T. Kudryavtsen, K.M. Tyutina, L.V. Kosmodamianskaya, Author's Certificate No. 314819 (USSR), Bull. 28, 1971.

[9] P.S. Tukmanova, G.I. Shulpin, N.V. Timin, Author's Certificate No. 570661 (USSR), Bull. 32, 1977.

[10] V.V. Gurylev, Ye.T. Yegorova, L.A. Simonova, Author's Certificate No. 808563 (USSR), Bull. 8, 1981.

[11] O. Bersirova, V. Kublanovsky, Mater. Sci. 48(2) (2012) 197-202. 